\title{
An Observation on Bending Fatigue Crack in Boronized Steels*
}

\author{
By Takashi Endoh** and Mamoru Kawakami**
}

\begin{abstract}
Plane and rotating bending fatigue tests of boronized steels with various thicknesses of boronized layers were conducted. The effect of the thickness of boronized layer on the crack initiation and propagation mechanism was investigated by fatigue crack observation. Many cracks propagating perpendicular to the tensile axis and those propagating parallel to it with connecting each other to spall the boronized layer, were observed. Fatigue cracks were observed also in a specimen which was not fractured up to the cyclic number $10^{7}$. But all those cracks were arrested either in the boronized layer or in a boundary between the boronized layer and the matrix. Fracture was controlled by whether the crack propagated through the boundary or not. Fatigue strength of boronized specimens with $\mathrm{Fe}_{2} \mathrm{~B}$ uni-layer was higher than that of boronized specimens with $\mathrm{FeB}+\mathrm{Fe}_{2} \mathrm{~B}$ bi-layer. The maximun fatigue strength was obtained, when the volume of $\mathrm{Fe}_{2} \mathrm{~B}$ layer was controlled so as to be about $1.5 \%$ of the total volume.
\end{abstract}

(Received June 26, 1984)

Keywords: boronized steels, surface hardening, plane bending fatigue test, rotating bending fatigue test, fatigue strength, fatigue crack observation

\section{Introduction}

The boronized process is famous as one of the chemical methods to achieve case hardening of steels. There have been a number of studies of treatment process and boronized layer. Vickers hardness number of the boronized layer exceeds 1400, and it has high resistance against wear, high temperature oxidation and corrosion ${ }^{(1)-(8)}$. In spite of these useful characteristics, the boronized process is not widespread. One of the reasons may be due to the fact that the mechanical properties of boronized layer were not thoroughly made clear. The authors have reported the distribution of residual stresses ${ }^{(9)}$ and tensile properties $^{(10)}$ in boronized steels.

There have been some studies on the fatigue strength $^{(11)-(13)}$ of boronized steels. However, the influence of thickness of boronized layer on the fatigue strength is not still made clear in detail. Also the influence of the type difference between $\mathrm{Fe}_{2} \mathrm{~B}$ uni-layer and $\mathrm{FeB}+\mathrm{Fe}_{2} \mathrm{~B}$ bilayer is not made clear. Then also the studies of observations on fatigue cracking were reported $^{(12)(13)}$, but all of them observed the

* This paper was originally published in Japanese in $\mathrm{J}$. Japan Inst. Metals, 48 (1984), 91.

** Department of Metallurgical Engineering, Faculty of Engineering, Tokai University, Tokyo 151, Japan. behavior of crack initiation and propagation during the fatigue process of only finally fractured specimens in which the stress amplitude exceeded the fatigue limit, and investigated the effect of thickness of boronized layer on crack initiation and propagation.

In the present study, plane and rotating bending fatigue tests of electrically boronized steels with various thicknesses of boronized layers were conducted. Effects of the thickness of boronized layer and stress amplitude on the fatigue strength were investigated quantitatively. Fatigue crack initiation and the propagation mechanism were investigated by crack observation. Fatigue cracks were observed also in a specimen which was not fractured in cyclic number $10^{7}$. But all those cracks were arrested either in the boronized layer or in a boundary between the boronized layer and the matrix.

\section{Experimental}

Materials fatigue tested were 0.35 mass $\% \mathrm{C}$ steel for plane bending and 0.50 mass $\% \mathrm{C}$ steel for rotating bending.

In this experiment, two different load application systems of bending fatigue are adopted. At the beginning of experiment, the effect of load application systems of the fatigue limit was unknown, because the data of fatigue test of boronized steels were insufficient. In 
both systems, we treated smooth specimens. On bending fatigue tests of liquid-nitrided steels, Asami reported that any effect of load application systems on the fatigue limit was absent in smooth specimens ${ }^{(14)}$. Therefore, we considered two different load application systems as the same. As a result, when the crack initiation occurred from the surface of boronized layer, the effect of load application system on the fatigue limit was not found.

Two kinds of materials of different carbon concentrations were used. In the boronized process, carbon in the boronized layer is pushed out into the matrix side and redistributed. Consequently, when the crack initiation occurs only from the inside of boronized layer, the effect of carbon content is negligible.

The boronized process was conducted by the electrical method. The surface of diffusion layer consisted of $\mathrm{FeB}$, below which $\mathrm{Fe}_{2} \mathrm{~B}$ was formed. The volume ratio of $\mathrm{FeB}$ layer to $\mathrm{Fe}_{2} \mathrm{~B}$ layer was nearly 1 to 1 . By the non-electrical holding after the boronized process, $\mathrm{Fe}_{2} \mathrm{~B}$ unilayer was also obtained. $\mathrm{Fe}_{2} \mathrm{~B}$ uni-layer specimens were used in the plane bending fatigue test, and both $\mathrm{FeB}+\mathrm{Fe}_{2} \mathrm{~B}$ bi-layer and $\mathrm{Fe}_{2} \mathrm{~B}$ uni-layer specimens were used in the rotating bending fatigue test. Conditions for electrical boronization applied to specimens are listed in Table 1. Fatigue cracks at the surface and on the cross section were observed in both fractured specimens and those not fractured up to $10^{7}$ stress cycles.

\section{Results}

Figure 1 shows S-N curves of plane bending test. It indicates also the results of non-boronized specimens as quenched and tempered. In case of short fatigue life, in which the number of fracture stress cycles $\left(N_{f}\right)$ is less than $10^{5}$, the fatigue strength of specimens with $\mathrm{Fe}_{2} \mathrm{~B}$ layer depth of $150 \mu \mathrm{m}$ was higher than that with 20 $\mu \mathrm{m}$ depth. On the contrary, in case of long

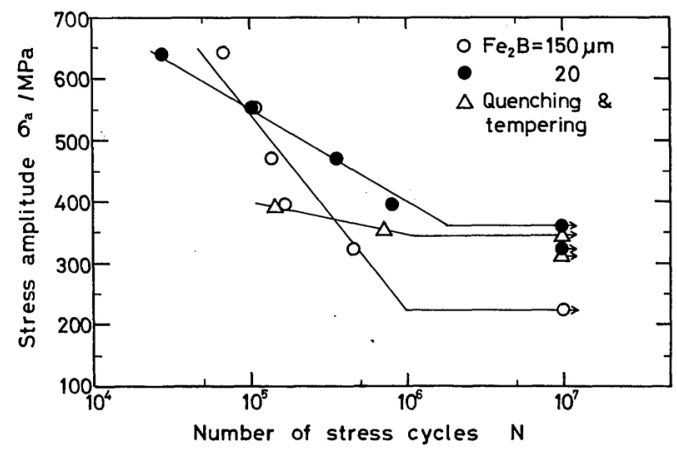

Fig. 1 S-N curves of boronized plane bending fatigue specimens.

Table 1 Condition for electrical boronization.

(a) Plane bending fatigue specimen.

\begin{tabular}{ccccccc}
\hline \hline $\begin{array}{c}\text { Salt } \\
\text { composition } \\
(\mathrm{mass} \%)\end{array}$ & $\begin{array}{c}\text { Temperature } \\
(\mathrm{K})\end{array}$ & $\begin{array}{c}\text { Current } \\
\text { density } \\
\left(\mathrm{A} / \mathrm{m}^{2}\right)\end{array}$ & $\begin{array}{c}\text { Time } \\
(\mathrm{s})\end{array}$ & $\begin{array}{c}\text { Boronized } \\
\text { layer }\end{array}$ & $\begin{array}{c}\text { Boronized } \\
\text { depth } \\
(\mu \mathrm{m})\end{array}$ & $\begin{array}{c}\text { Cooling } \\
\text { method }\end{array}$ \\
& & 500 & $1.44 \times 10^{4}$ & $\mathrm{Fe}_{2} \mathrm{~B}$ & 150 & In $\mathrm{N}_{2}-\mathrm{gas}$ \\
$\mathrm{Na}_{2} \mathrm{~B}_{4} \mathrm{O}_{7}-100$ & 1173 & 0 & $0.72 \times 10^{4}$ \\
& & 700 & $1.80 \times 10^{3}$ & $\mathrm{Fe}_{2} \mathrm{~B}$ & 20 & \\
\hline \hline
\end{tabular}

(b) Rotating bending fatigue specimen.

\begin{tabular}{|c|c|c|c|c|c|c|}
\hline $\begin{array}{c}\text { Salt } \\
\text { composition } \\
(\operatorname{mass} \%)\end{array}$ & $\begin{array}{l}\text { Temperature } \\
(\mathrm{K})\end{array}$ & $\begin{array}{l}\text { Current } \\
\text { density } \\
\left(\mathrm{A} / \mathrm{m}^{2}\right)\end{array}$ & $\underset{(s)}{\text { Time }}$ & $\begin{array}{c}\text { Boronized } \\
\text { layer }\end{array}$ & $\begin{array}{l}\text { Boronized } \\
\text { depth } \\
(\mu \mathrm{m})\end{array}$ & $\begin{array}{l}\text { Cooling } \\
\text { method }\end{array}$ \\
\hline \multirow{6}{*}{$\mathrm{Na}_{2} \mathrm{~B}_{4} \mathrm{O}_{7}-100$} & \multirow{6}{*}{1173} & 500 & $1.44 \times 10^{4}$ & $\mathrm{FeB}+\mathrm{Fe}_{2} \mathrm{~B}$ & 60 & \multirow{6}{*}{ In $\mathrm{N}_{2}$-gas } \\
\hline & & 500 & $1.44 \times 10^{4}$ & $\mathrm{Fe}_{2} \mathrm{~B}$ & 60 & \\
\hline & & 0 & $0.72 \times 10^{4}$ & $\mathrm{Fe}_{2} \mathrm{~B}$ & 00 & \\
\hline & & 700 & $1.80 \times 10^{3}$ & $\mathrm{FeB}+\mathrm{Fe}_{2} \mathrm{~B}$ & 20 & \\
\hline & & 700 & $1.80 \times 10^{3}$ & \multirow{2}{*}{$\mathrm{Fe}_{2} \mathrm{~B}$} & \multirow[b]{2}{*}{20} & \\
\hline & & 0 & $1.20 \times 10^{3}$ & & & \\
\hline
\end{tabular}


fatigue life, in which $N_{f}$ is more than $10^{5}$, both the fatigue strength and fatigue limit of specimen with layer depth of $20 \mu \mathrm{m}$ was higher than that with layer depth of $150 \mu \mathrm{m}$.

Figure 2 shows fatigue curves of rotating bending test. In case of $\mathrm{Fe}_{2} \mathrm{~B}$ uni-layer specimen, both the fatigue strength and fatigue limit of layer depth of $60 \mu \mathrm{m}$ were higher than those of $20 \mu \mathrm{m}$. In case of $\mathrm{FeB}+\mathrm{Fe}_{2} \mathrm{~B}$ bi-layer specimen, as in the plane bending test, two fatigue curves of layer depths of $60 \mu \mathrm{m}$ and 20 $\mu \mathrm{m}$ intersect each other.

Many macro cracks were observed on the surface of fractured plane bending specimens. It was made clear that those cracks were propagated connecting each other, from the presence of the cracks propagated parallel to the tensile axis. On the other hand, many cracks were distributed also in the specimen which was not fractured up to the cyclic number $10^{7}$. An example in which $\mathrm{Fe}_{2} \mathrm{~B}$ layer depth is $150 \mu \mathrm{m}$ is shown in Fig. 3. Also in case of layer depth of $20 \mu \mathrm{m}$, similar cracks were observed. It was thought that brittle cracks characteristic of the boronized layer were initiated and propagated.

Next the results of observation of crack initiation and propagation on the cross section, are indicated. Both in case of plane bending and rotating bendig, the behavior of crack initiation and propagation was changed, mainly according to the difference in stress amplitude.

Micrographs in Fig. 4 represents cross sectional cracks in plane bending specimens $\left(\mathrm{Fe}_{2} \mathrm{~B}\right.$

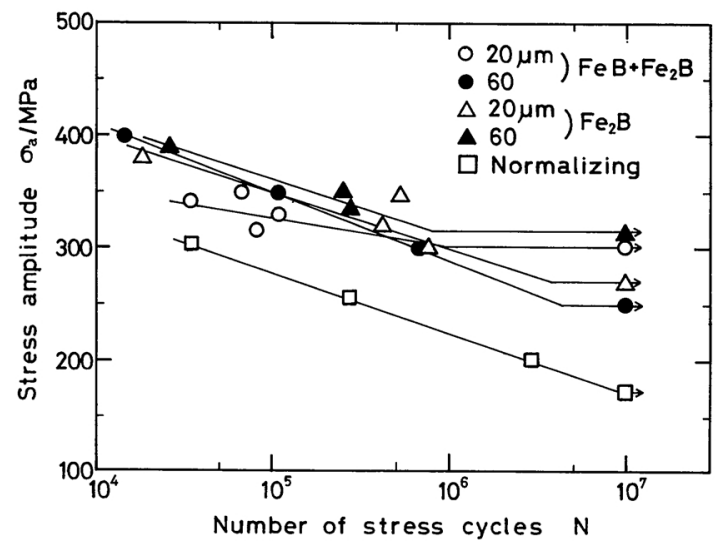

Fig. 2 S-N curves of boronized rotating bending fatigue specimens.

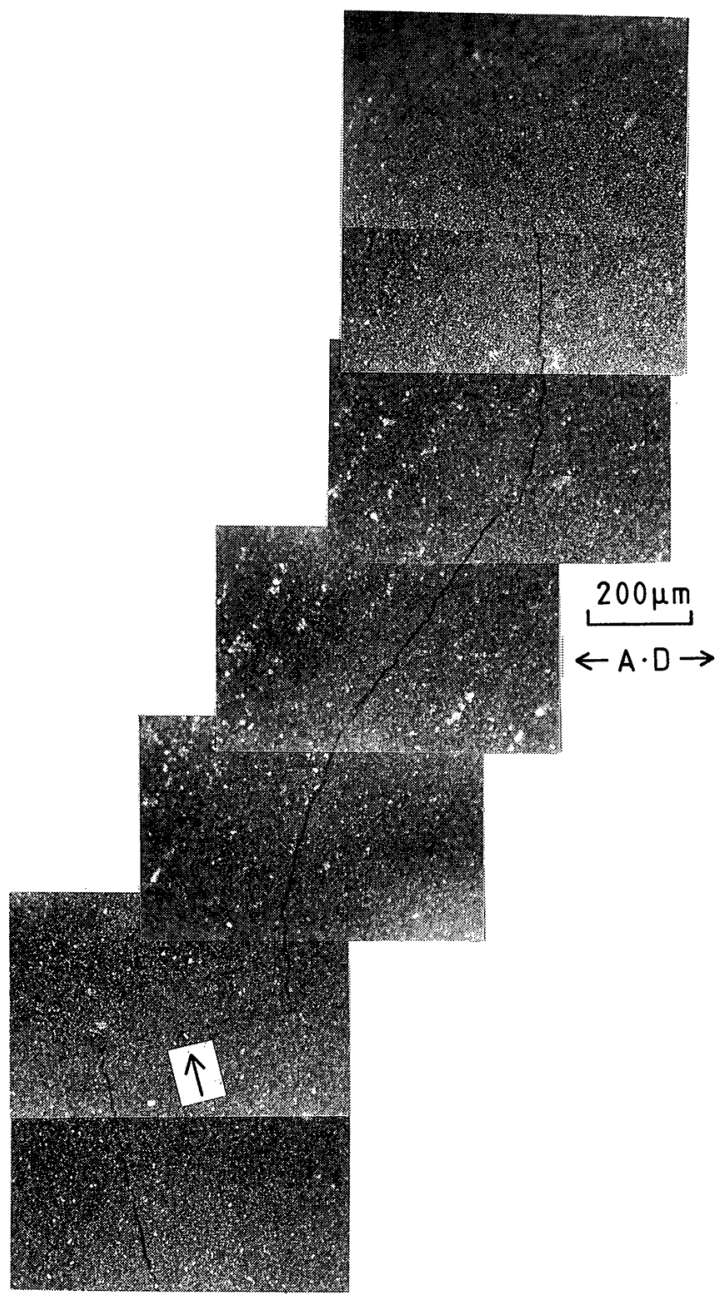

Fig. 3 Micrograph of surface crack observed in plane bending fatigue specimen, $\left(\mathrm{Fe}_{2} \mathrm{~B}=150 \mu \mathrm{m}, \sigma_{a}=223\right.$ $\mathrm{MPa}, N_{f}>10^{7}, \uparrow=$ Connected point of cracks)

layer depth is $150 \mu \mathrm{m}$ ). (a) is the case of high stress amplitude with $\sigma_{a}=556 \mathrm{MPa}$ and $N_{f}=1.1 \times 10^{5}$ and (b) is the case of low stress amplitude with $\sigma_{a}=223 \mathrm{MPa}$ and $N_{f}>10^{7}$. In the former case, many cracks were initiated from the neighborhood of the boundary between the boronized layer and the matrix, and propagated towards both the boronized layer and the matrix. It is understood from the fact that the crack opening displacement near the boundary is bigger than that at the surface. Many cracks, initiated from the surface and arrested either in the boronized layer or in the matrix by moving across the boundary, were 


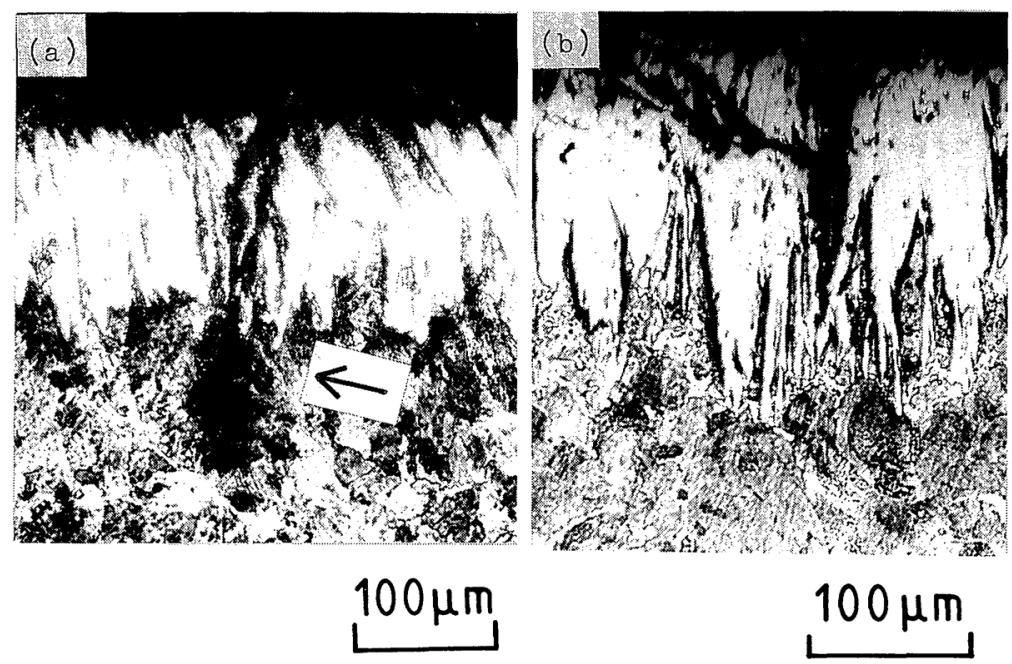

Fig. 4 Micrographs of cross sectional crack observed in plane bending fatigue specimen. $\left(\mathrm{Fe}_{2} \mathrm{~B}=150 \mu \mathrm{m}\right)$ (a) $\sigma_{a}=556 \mathrm{MPa}, N_{f}=1.1 \times 10^{5}$, $\uparrow=$ Initiated point of crack. (b) $\sigma_{a}=223$ $\mathrm{MPa}, N_{f}>10^{7}$.

also observed. Thus for the high stress amplitude range above $556 \mathrm{MPa}$, the crack initiation occurred from both the surface and neighborhood of the boundary. For the low stress amplitude range under $470 \mathrm{MPa}$, the crack initiation occurred from only the surface. Also in the latter case, many cracks were initiated as observed at the specimen surface. All those cracks were however, initiated from only the surface and arrested within the boronized layer, and they were not propagated through the boundary. Many cracks propagated also parallel to the tensile axis in the boronized layer along which the layer was spalled, were observed. Fracture was controlled by whether the crack was propagated through the boundary or not. Also in case of layer depth of $20 \mu \mathrm{m}$, similar cracks were observed. Both in case of $\mathrm{Fe}_{2} \mathrm{~B}$ uni-layer and $\mathrm{FeB}+\mathrm{Fe}_{2} \mathrm{~B}$ bi-layer on rotating bending, the behavior of crack initiation and propagation was changed, mainly according to the difference in stress amplitude, as in case of plane bending. When the stress amplitude $\left(\sigma_{a}\right)$ exceeded $330 \mathrm{MPa}$, the cracks were initiated from both the surface and the neighborhood of the boundary. When $\sigma_{a}$ did not exceed $320 \mathrm{MPa}$, they were initiated only from the surface. The cracks under the fatigue limit were arrested within the boundary. Over all the stress amplitude range, in case of thin $\mathrm{Fe}_{2} \mathrm{~B}$ uni-layer of $20 \mu \mathrm{m}$, however, the crack initiation occurred from both the surface and the neighborhood of the boundary, and any cracks were not observed under the fatigue limit.

\section{Discussion}

From the results of fatigue crack observation, it is made clear that the critical value of stress amplitude changing the crack initiation point exists. Above the critical value range, the crack initiation occurs from both the surface and the neighborhood of the boundary. Under this range, the crack initiation occurs only from the surface.

Kogan reported on the crack observation during the plane bending fatigue process by using $\mathrm{FeB}+\mathrm{Fe}_{2} \mathrm{~B}$ bi-layer specimens in almost the same ratio range of boronized layer depth as in the present study ${ }^{(13)}$. According to Kogan's report, the ratio of boronized layer depth has an effect mainly on changing the crack initiation point. The crack initiation almost always occurs beneath the boronized layer. This result appears to be inconsistent with the present study.

We shall thus consider the cause for crack ar- 
rest in the boronized layer. In the first place, it is expected that many cracks initiated from the surface and propagated perpendicular to the tensile axis, connecting each other so as to spall the boronized layer, eliminate the notch effects in the crack growth, because the notch radius was increased by connection of cracks. Secondary, it is considered that the cracks propagated to the boundary without connection are arrested by the resistance against crack growth of any different material such as the matrix, as observed in the fatigue crack in composite materials. It is considered that the increase in strength of the matrix by carbon redistribution has an effect on the crack arrest.

As for macroscopic factors changing the fatigue strength of the hard surface materials, change in surface material and compressive residual stress in the boronized layer are pointed out. In boronized steels the contribution of change in surface material to increase of fatigue strength is a little, because, as indicated in Fig. 2, the fatigue strength of specimen with $\mathrm{Fe}_{2} \mathrm{~B}$ layer depth of $150 \mu \mathrm{m}$ was lower than that of non-boronized specimen.

The authors found the existence of high compressive residual stress in the boronized layer by X-ray residual stress measurements ${ }^{(9)}$. The distribution of the stress depends both on the difference in thermal expansion coefficient between the adjoining phases as well as on the difference in specific volume between the boronized layer and the matrix. The smaller the ratio of specific volume of the boronized layer, the higher the value of compressive residual stress. In the present plane bending fatigue specimens, the values of compressive residual stress in $150 \mu \mathrm{m}$ and $20 \mu \mathrm{m}$ layer depths of $\mathrm{Fe}_{2} \mathrm{~B}$ phase were $1200 \mathrm{MPa}$ and 2000 $\mathrm{MPa}$, respectively. When a crack is initiated from the surface, this compressive residual stress has an effect of obstructing the crack initiation and propagation. In case of $20 \mu \mathrm{m}$ layer depth of $\mathrm{Fe}_{2} \mathrm{~B}$ uni-layer with a high stress value, it is considered that the fatigue limit is the highest. On the other hand, when the crack initiation occurs from the neighborhood of the boundary as in short fatigue life, this compressive residual stress has no effect. On the other hand, tensile residual stress which is distributed near the boundary has a bad effect, the value of tensile residual stress in $20 \mu \mathrm{m}$ layer depth is higher than that in $150 \mu \mathrm{m}$ layer depth. As the value of bending stress applied to the boundary of thin layer depth is higher than that in thick layer depth, it is considered that the fatigue limit becomes low by these effects. The change in crack initiation point due to these effects contributes to the crossing of the S-N curves.

Also in case of $\mathrm{Fe}_{2} \mathrm{~B}$ layer depth of $20 \mu \mathrm{m}$ in rotating bending test, as tensile residual stress and bending stress near the boundary are high, crack initiation occurs from the neighborhood of the boundary in all stress amplitudes and the fatigue limit becomes low.

It was made clear in boronized steels that the most appropriate volume ratio of boronized layer existed for the maximum fatigue limit, because the most effective factor to increase the fatigue strength is the surface compressive residual stress. Figure 5 shows the relation between the fatigue limit and the volume ratio of boronized layer. The maximum fatigue limit is obtained, when the volume of $\mathrm{Fe}_{2} \mathrm{~B}$ layer is controlled so as to be about $1.5 \%$ of the total volume. The fatigue limit of boronized specimens with $\mathrm{Fe}_{2} \mathrm{~B}$ uni-layer was higher than that of boronized specimens with $\mathrm{FeB}+\mathrm{Fe}_{2} \mathrm{~B}$ bi-layer. These results practically agree with the ratio of the most appropriate thickness that Kogan pointed out ${ }^{(13)}$.

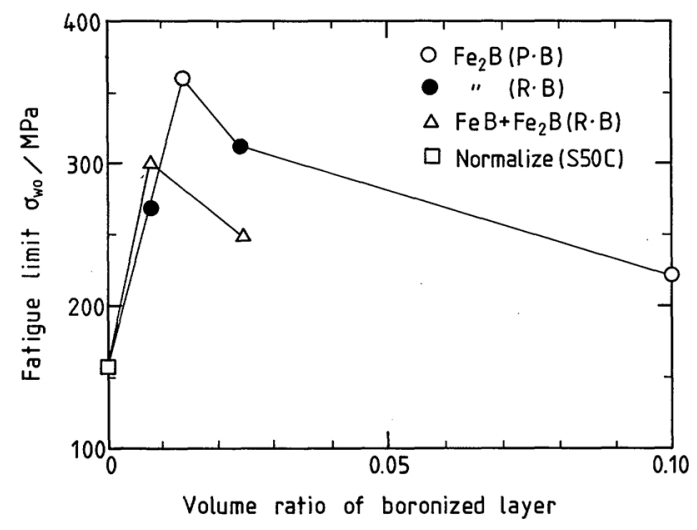

Fig. 5 Relation between fatigue limit and volume ratio of boronized layer. (P. B = Plane Bending, R. B=Rotating Bending) 


\section{Conclusion}

Plane and rotating bending fatigue tests of boronized steels with various thicknesses of boronized layers were conducted, and fatigue cracks were observed. The following results were obtained.

(1) Many cracks propagating perpendicular to the tensile axis and those propagating parallel to the tensile axis, connecting each other to spall the boronized layer, were observed.

(2) Fatigue cracks were observed also in the specimens which were not fractured up to the cyclic number $10^{7}$. But all those cracks were arrested either in the boronized layer or in a boundary between the boronized layer and the matrix. Fracture was controlled by whether the crack propagated through the boundary or not.

(3) The fatigue strength of boronized specimens with $\mathrm{Fe}_{2} \mathrm{~B}$ uni-layer was better than that of boronized specimens with $\mathrm{FeB}+\mathrm{Fe}_{2} \mathrm{~B}$ bi-layer. The maximum fatigue strength was obtained, when the volume of $\mathrm{Fe}_{2} \mathrm{~B}$ boronized layer was controlled so as to be about $1.5 \%$ of the total volume.

\section{REFERENCES}

(1) M. Kawakami: B. Japan Inst. Metals., 4 (1965), 623 (in Japanese).

(2) N. Takamoto, T. Katagiri, K. Fujii and Y. Katagiri: J. Japan Inst. Metals., 31 (1967), 338 (in Japanese).

(3) T. Katagiri, K. Fujii and N. Takamoto: J. Japan Inst. Metals., 31 (1967), 904 (in Japanese).

(4) T. Katagiri, K. Fujii and N. Takamoto: J. Japan Inst. Metals., 32 (1968), 848 (in Japanese).

(5) A. Muta, G. Toda and H. Shimanoki: J. Japan Inst. Metals., 31 (1967), 296 (in Japanese).

(6) K. Fujii, T. Katagiri, E. Takeuchi, K. Chiba and T. Saga: J. Japan Inst. Metals., 40 (1976), 360 (in Japanese).

(7) Y. Shibuya: J. Soci. Mat. Sci. Jap., 26 (1977), 120.

(8) Y. Shibuya, Y. Imazawa and K. Kuwana: J. Iron Steel Inst., 66 (1980), 532 (in Japanese).

(9) T. Endoh and M. Kawakami: J. Soci. Mat. Sci. Jap., 32 (1983), 115.

(10) T. Endoh, Y. Watanabe and M. Kawakami: Collected Abstracts 1980 Autumn Meeting (87th Conv.) of JIM, Fukuoka (1980), p. 362 (in Japanese).

(11) K. Asami: J. Jap. Soci. Heat. Treat., 21 (1981), 70.

(12) E. Scheiber and M. Riehle: Neue Hütte., 19 (1974), 38.

(13) R. L. Kogan, G. V. Zemskov, N. N. Dorofeev and E. L. Kishinevskii: Fiz.-Khim. Mekh. Mat., 5 (1972), 26.

(14) K. Asami: Jitsumu Hyōmen Gijutsu., 29 (1982), 80. 